\title{
Intellectual Information and Training System for Software and Hardware Complexes of Morphological Diagnostics of Esophageal Tumors
}

\author{
Nikitaev V.G. ${ }^{1}$, Pronichev A.N. ${ }^{1}$, Selchuk V. Y. ${ }^{1,2}$, Tavrina N.S. ${ }^{1}$, Dmitrieva V.V. ${ }^{1}$, \\ Polyakov E.V. ${ }^{1}$, and Druzhinina E.A. ${ }^{1}$
}

${ }^{1}$ National Research Nuclear University MEPhl (Moscow Engineering Physics Institute), Kashirskoe shosse 31, 115409, Moscow, Russia

${ }^{2}$ N.N. Blokhin Russian Cancer Research Center, Kashirskoe shosse 23, 115478, Moscow, Russia

\section{Abstract}

The aim of the work is to create a system of formalizing knowledge in the histological diagnosis of esophageal tumors and systematic transfer of knowledge to less experienced specialists. It is also a system that will provide support in making a

Corresponding Author:

V. Nikitaev

VGNikitayev@mephi.ru

Received: 17 January 2018

Accepted: 25 March 2018

Published: 17 April 2018

Publishing services provided by Knowledge E

(c) Nikitaev V.G. et al. This article is distributed under the terms of the Creative Commons

Attribution License, which permits unrestricted use and redistribution provided that the original author and source are credited.

Selection and Peer-review under the responsibility of the PhysBioSymp17 Conference Committee. decision in a histological diagnosis.

Keywords: esophagus, morphological, automatic work place, system of support for the solution

\section{Introduction}

To date, one of the most urgent problems of oncology is the improvement of the quality of early morphological diagnosis of cancer, in particular, cancer of the esophagus. There is no doubt that timely diagnosis is a reserve that will change the situation with the treatment and survival of patients for the better along with other factors. However, this problem (early diagnosis) is complicated by the presence of a large variety of forms of malignant processes, rather complex systems of signs used to verify the morphological diagnosis and their weak formalization. Therefore, the qualification and experience of pathomorphologists participating in the diagnosis is extremely important here, since the final diagnosis is based on the results of the morphological histological research and the tactics of the patient's treatment are determined [1-7]. 


\section{Materials and Methods}

To achieve the goals, it was necessary to conduct a thorough analysis of the subject area, taking into account its specifics, including the system, data and training module. At the final stage, it was necessary to conduct a series of tests and to conduct testing with the help of young pathologists of the Russian Cancer Research Center named after NN. Blokhin, correct mistakes and comments revealed during the testing and development of custom techniques for various categories of users of the system [8].

For the entry of any System of Support for the Solution, a database is included, at the next stage of development work was done on the design of the database of the system.

Chart options use information and training system in histological diagnosis of tumors of the esophagus in Fig.1.General scheme of actions for working with the system. Diagram of options for using the training information system for histological diagnosis of tumors of the esophagus in Figure1.

The core entity, according to the subject area, is a Case that can include several images of histological microscopic specimens of one patient. The remaining entities are associative or entity-characteristics.

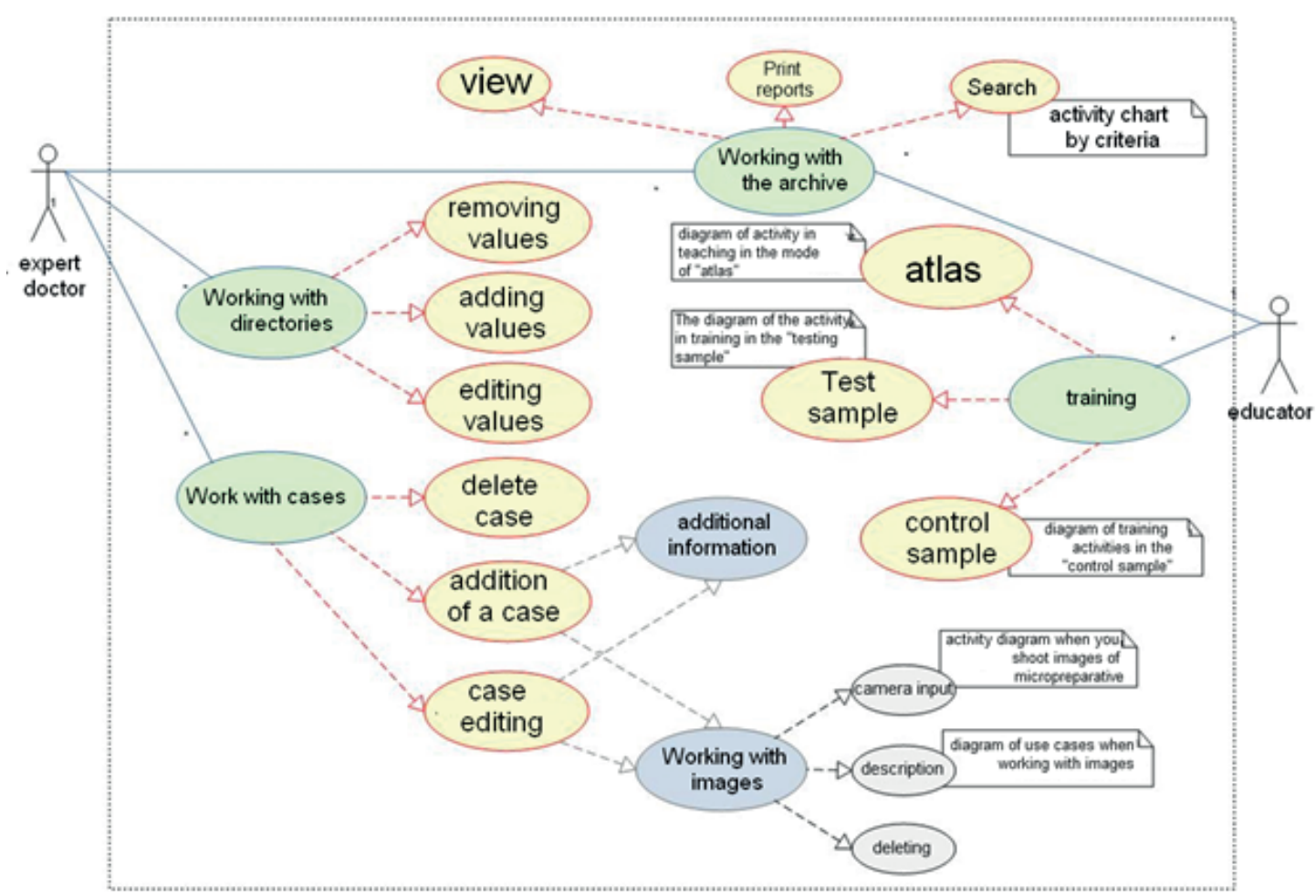

Figure 1: Diagram of options for using the training information system for histological diagnosis of tumors of the esophagus. 
As the database system, Oracle gi was chosen, which allows to operate a large amount of information and at the same time providing a degree of their reliability and protection. SQL Navigator 5.

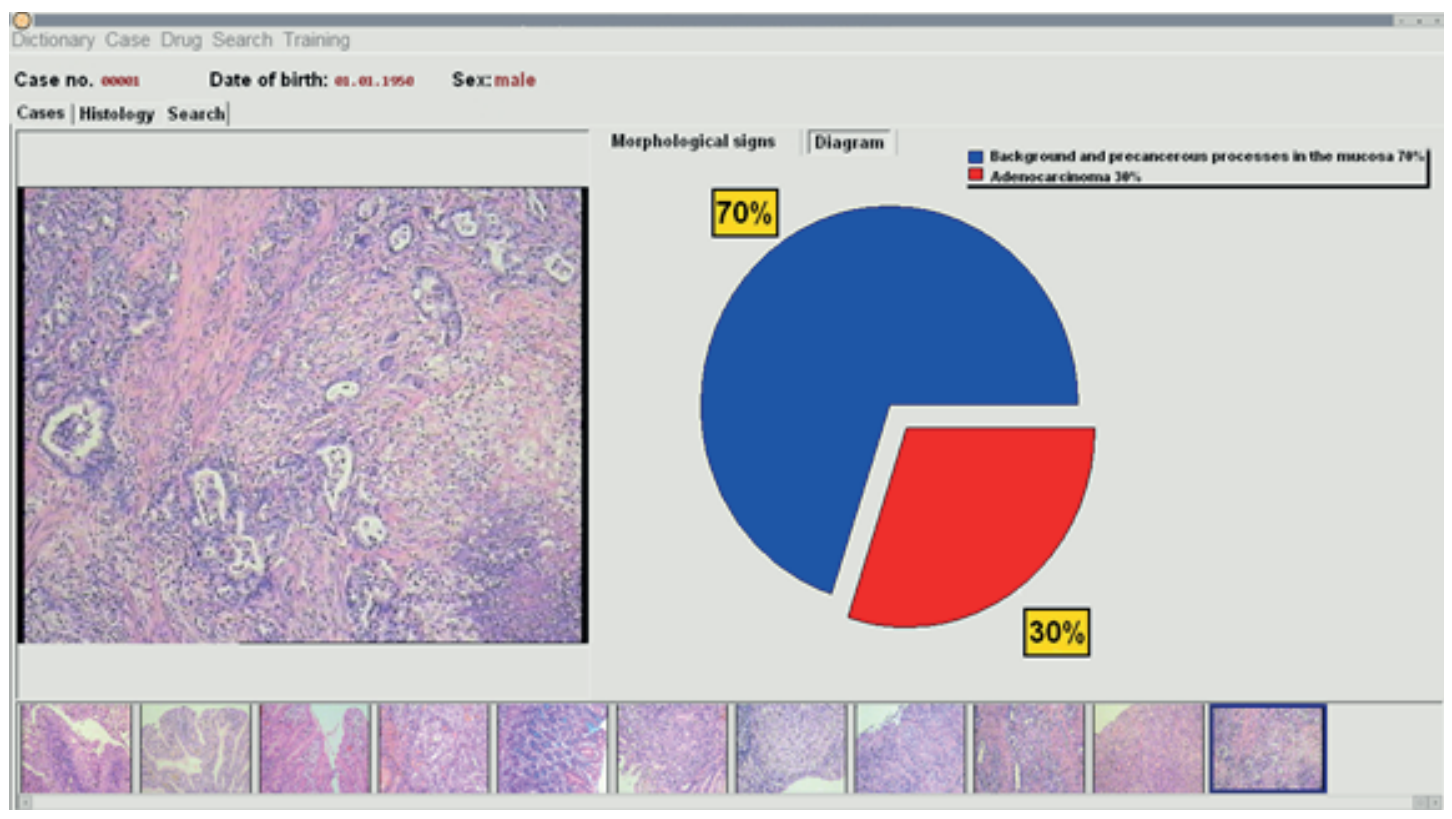

Figure 2: Search results presented as a pie chart.

\section{Results}

As a result of the analysis of the subject area and the object environment, two main categories of users are identified: pathologist-expert and trained physician, for which Automated Work Places should be developed. The AWP of an expert pathomorphologist differs from the trained physician's AWP with the presence of a microscope and a video camera for image input, the shell of the system to form sets of histological signs and their meanings and a list of nosological forms for describing the input images. An expert doctor can work with the archive, with reference books and cases. The inexperienced specialist, in turn, can work with the archive of images, can get consultations and undergo training in various modes (Figure 2) [8-13].

The conceptual model of an intellectual information-training system for software and hardware complexes of morphological diagnostics of esophageal tumors includes: a training system, a knowledge base, an expert system. The modes of operation have been developed: the "Atlas" regimes, the control sample and the training sample. The modes have been successfully tested in the "National Medical Research Center of Oncology. N.N. Blokhin" with the participation of young specialists. Filling the database 
of the information and training system with histological images of tumor and precancerous processes in the esophagus was carried out using archival and advisory materials of the "National Medical Research Center of Oncology. N.N. Blokhin ". According to the conclusions of the expert doctors, the developed information system implements all the necessary functions and capabilities to improve the quality of morphological histological diagnostics and professional development of young specialists.

\section{Conclusions}

In the course of the work, an information and training system was developed to support the adoption of medical decisions in the histological diagnosis of tumors of the esophagus. The system allows the expert doctor to fill in and correct the database of the system with minimal time and effort. And for the trained physician the system allows to check the level of their knowledge, compare the solutions of problems with the reference ones, and analyze the results obtained.

One of the main directions for improving the system is the creation of an information and training system to support the decision-making of the expert system for the automated establishment of a preliminary morphological diagnosis using imaging techniques.

\section{Acknowledgement}

This work was supported by the MEPhl Academic Excellence Project (agreement with the Ministry of Education and Science of the Russian Federation of August 27, 2013, project no. 02.a03.21.0005).

\section{References}

[1] S.M. Zaytsev et al, A method of data structuring in the decision making support system in oncological diagnostics of prostate diseases, Journal of Physics: Conference Series, 798(1), 012132, (2017).

[2] D.Yu. Pushkar, P.I. Rasner differencial'naya diagnostika raka i dobrokachestvennoj giperplazii predstatel'noj zhelezy, Russkij medicinskij zhurnal, vol. 22, no. 17, pp.1298-1303, 2014,

[3] J.T. Kwak, S.M. Hewitt, A.A. Kajdacsy-Balla, S. Sinha, R. Bhargava, Automated prostate tissue referencing for cancer detection and diagnosis, BMC Bioinformatics, 
vol. 17, no. 1, 227, 2016.

[4] M.V. Kovylina, E. A. Prilepskaya, A. V. Govorov, V. V. D'iakov, K. B. Kolontarev, A. O. Vasilyev, A.V. Sidorenkov, P.I. Rasner, A.V. Glotov, D. Yu. Pushkar', V. G. Nikitaev and A. N. Pronichev, "Benign mimics of prostatic adenocarcinoma", Urologiia (Moscow, Russia : 1999), vol. 6, pp. 51-56, 2014.

[5] E. A. Prilepskaya, M.V. Kovylina, A. V. Govorov, A. V. Glotov, A. O. Vasilyev, K. B. Kolontarev, V. G. Nikitaev, A. N. Pronichev and D. Yu. Pushkar, "Possibilities of automated image analysis in pathology", Arkhiv Patologii, vol. 78, no. 1, pp. 51-55, 2016.

[6] S. M. Zaytsev, V.G. Nikitaev, A.N. Pronichev, B.N. Onykiy, E.V. Polyakov, A.A. Kurdin, D.Y. Pushkar, E.A. Prilepskaya, M.V. Kovilina, A.V. Govorov, A.V. Glotov, A.O. Vasilyev and K.V. Kolontarev "Computer system for remote consultations in the diagnosis of urological malignancies", Journal of Physics: Conference Series, vol. 798, no. 1, p. 012133, 2017.

[7] S. M. Zaytsev, V.G. Nikitaev, A.N. Pronichev, O.V. Nagornov, E.V. Polyakov, N.A. Romanov, D.Y. Pushkar, E.A. Prilepskaya, M.V. Kovilina, A.V. Govorov, A.V. Glotov, A.O. Vasilyev and K.V.Kolontarev "A method of data structuring in the decisionmaking support system in oncological diagnostics of prostate diseases", Journal of Physics: Conference Series, vol. 798, no. 1, p. 012132, 2017.

[8] M. I. Davydov, V. Y. Selçuk, V. G. Nikitaev, O. V. Nagornov, A. N. Pronichev, V. V. Dmitriev, E. V. Polyakov, A. O. Rasulov, V. P., Kononets, S. A. Melikhov, I. S. Akimov, Z. M. Yunakov, I. V. Kardashev, A. A. Lavrova, V. K. Golovanov, A. A., Pasnik and V. E. Strigin, "Physical research methods in expert systems of oncological disease diagnostics" Bulletin of the Lebedev Physics Institute, vol. 42, no. 8, pp 237-239, 2015 .

[9] V. G. Nikitaev, A. N. Pronichev, E. V. Polyakov, V. V. Dmitrieva, N. N. Tupitsyn, M. A. Frenkel and A. V. Mozhenkova, "Application of texture analysis methods to computer microscopy in the visible range of electromagnetic radiation" Bulletin of the Lebedev Physics Institute, vol. 43, no. 10, pp 306-308, 2016.

[10] V. G. Nikitaev, "Methods and means of diagnostics of oncological diseases on the basis of pattern recognition: Intelligent morphological systems - Problems and solutions" Journal of Physics: Conference Series, vol. 798, no. 1, p. 012131, 2017.

[11] V. G. Nikitaev, "Expert Systems in Information Measuring Complexes of Oncological Diagnoses" Measurement Techniques, vol. 58, no. 6, pp. 719-723, 2015.

[12] V. G. Nikitaev, "Modern measurement principles in intellectual systems for a histological diagnosis of oncological illnesses" Measurement Techniques, vol. 58, no. 4, pp. 467-470, 2015. 
[13] V. G. Nikitaev, "Medical and biological measurements: Experimental hightechnology information-measuring complexes of cancer diagnosis: Problems and key points of the construction methodology" Measurement Techniques, vol. 58, no. 2, pp. 214-218, 2015. 